\title{
Equipamentos de saúde e processos de atenção: Tópicos para pensar ações do Estado voltadas aos povos indígenas
}

Health care equipments and care processes: topics to think about of the State oriented actions for indigenous peoples

\section{Nádia Heusi Silveira}

\section{(2) OpenEdition Journals}

\section{Edição electrónica}

URL: http://journals.openedition.org/aa/2949

DOI: $10.4000 /$ aa. 2949

ISSN: 2357-738X

\section{Editora}

Programa de Pós-Graduação em Antropologia Social (UnB)

\section{Edição impressa}

Data de publição: 1 julho 2018

Paginação: 197-222

ISSN: 0102-4302

\section{Refêrencia eletrónica}

Nádia Heusi Silveira, «Equipamentos de saúde e processos de atenção: Tópicos para pensar ações do Estado voltadas aos povos indígenas», Anuário Antropológico [Online], v.43 n. 1 | 2018, posto online no dia 26 maio 2019, consultado o 28 abril 2021. URL: http://journals.openedition.org/aa/2949 ; DOI: https://doi.org/10.4000/aa.2949

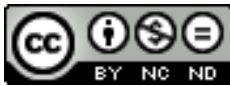

Anuário Antropológico is licensed under a Creative Commons Atribuição-Uso Não-Comercial-Proibição de realização de Obras Derivadas 4.0 International. 


\title{
Equipamentos de saúde e processos de atenção Tópicos para pensar ações do Estado voltadas aos povos indígenas
}

\author{
Nádia Heusi Silveira \\ INCT Brasil Plural
}

\section{Introdução}

O propósito deste artigo é analisar a ação do Estado no que diz respeito aos povos indígenas a partir do planejamento de uma política orientada ao consumo abusivo de álcool e drogas entre os Kaiowa e Guarani ${ }^{1}$. Apesar destes povos terem sido o foco da ação, o processo descrito a seguir ainda não se tornou visível para os Kaiowa e Guarani que vivem nas aldeias em Mato Grosso do Sul, praticamente restringindo-se às relações entre agentes de distintos setores do Estado que trabalhavam nos níveis central e local. Assim, não está em questão o formato e os efeitos que tais políticas assumiram desde a perspectiva dos próprios Kaiowa e Guarani, já que sua presença naquele cenário funcionou apenas como participação virtual, projeção de futuro ou ideário de certa cultura.

A abordagem é dada desde um engajamento como agente de Estado, vinculada à sede do órgão indigenista, a Fundação Nacional do Índio, FUNAI, em Brasília $^{2}$. O assunto ambientou-se em um conjunto de atribuições e atividades ligadas exclusivamente à pauta dos Kaiowa e Guarani, que era uma prioridade para a presidência do órgão. Envolvi-me nas discussões com o intuito de favorecer a operacionalização de um conjunto de ações que estavam em vias de ser elaboradas e desenvolvidas.

Com o intuito de abordar o Estado como um modo específico de olhar um conjunto de processos e práticas, bem como seus efeitos, conforme define Trouillot (2001), o processo de negociação para a implementação de "Ações integradas de enfrentamento à violência no cone sul de Mato Grosso do Sul” será descrito e contextualizado. O processo tentativo de elaboração dessas ações colocou em interlocução e foi pactuado por vários órgãos do Estado: FUNAI, Departamento de Polícia Federal, Força Nacional de Segurança Pública, Ministério da Justiça, Secretaria de Direitos Humanos da Presidência da República, Secretaria de Articulação Social da Presidência da República e Ministério da 
Saúde, através da Secretaria Especial de Saúde Indígena (SESAI) e da Secretaria de Atenção à Saúde (SAS).

Procura-se explicitar a definição de Estado usada para descrever alguns processos e atividades que se desenrolaram no período aproximado de quatro ou cinco meses, bem como alocar os elementos considerados centrais para o argumento de que tais práticas e processos exprimem o poder tutelar, considerando ainda um conjunto de informações sobre a Reserva Indígena de Dourados e os modos de beber entre os Kaiowa e Guarani. O conceito de "poder tutelar", cunhado por Souza Lima (1995), de inspiração foucaultiana, refere-se à forma histórica característica da ação estatal desenvolvida sobre as ações de povos indígenas no Brasil e será retomado adiante. Como consequência do exercício deste poder nos dias atuais, evidenciou-se, ao longo das discussões para consensuar as diretrizes da ação, um interesse dominante em controlar o comportamento dos índios, em detrimento de um enfoque mais direcionado ao restabelecimento de sua saúde mental.

\section{Como o abuso de bebidas alcoólicas entre os Kaiowa e Guarani mobiliza o Estado}

Os problemas associados ao abuso de bebidas alcoólicas ${ }^{3}$ têm grande magnitude entre os Kaiowa e Guarani, uma vez que estão ligados, empiricamente, aos casos de violência intrafamiliar e entre os que convivem nas aldeias, à prática do suicídio e ao favorecimento da desnutrição infantil ${ }^{4}$, assuntos que de tempos em tempos são noticiados na mídia. Embora não existam dados consistentes sobre a prevalência do abuso de álcool entre os Kaiowa e Guarani, bem como para os povos indígenas em geral (Langdon, 2013), a convivência com os Kaiowa e Guarani nas aldeias inevitavelmente revela a complexidade e gravidade do fenômeno. Na última década, esse problema se exacerbou com o consumo de outras substâncias como cannabis, crack e solventes ${ }^{5}$, particularmente pelos jovens.

Na FUNAI, o processo de discussão de ações para os Kaiowa e Guarani, relativas ao abuso dessas substâncias, já está em andamento há alguns anos. O que catapultou esforços naquele momento, na virada de 2012 para 2013, foi o deparar-se com o assunto pela via das ações direcionadas à minimização da violência que estavam acontecendo intensivamente na Reserva Indígena de Dourados, no município de Dourados, Mato Grosso do Sul ${ }^{6}$. Nas primeiras interlocuções internas, entre as Coordenações Gerais que funcionam na sede da FUNAI e a 
Coordenação Regional de Dourados, evidenciaram-se diferentes pontos de vista.

Todos concordavam que eram necessárias e até urgentes medidas para diminuir o consumo de bebidas alcoólicas e drogas, mas o que fazer ou como encaminhar as ações nessa direção não era consenso. No âmbito das ações de segurança pública, desenhou-se a implantação de um Centro de Atenção Psicossocial Álcool e Drogas (CAPS AD) ${ }^{7}$ dentro da Reserva Indígena. Contudo, os agentes da sede da FUNAI que lidavam com as questões de saúde postulavam outro tipo de ações a serem construídas junto com os Kaiowa e Guarani, provavelmente voltadas para práticas de diálogo, aconselhamentos, e mais opções de trabalho e lazer, além de um componente biomédico a ser melhor avaliado. Os agentes locais da FUNAI também tendiam para esta segunda opção.

Num segundo momento, em que a FUNAI debateu o problema com agentes do Ministério da Saúde, da SAS e da SESAI, observou-se divergência semelhante. Localmente, os agentes que atuavam no Distrito Sanitário Especial Indígena de Mato Grosso do Sul (DSEI MS) pleiteavam a implantação de um CAPS AD Indígena e relatavam a dificuldade de conseguir vagas para o atendimento dos Kaiowa e Guarani nos dois únicos equipamentos deste tipo disponíveis na região, tendo mesmo que recorrer à via judicial. Os agentes da SAS e da SESAI, entretanto, alinhavam-se com a perspectiva de estudar com cautela uma solução que considerasse intervenções coletivas em vez de individuais. Propunham partir de um diagnóstico a ser realizado no DSEI MS, através da notificação de violências no âmbito da saúde ${ }^{8}$ e de outros dados psicossociais que pudessem subsidiar intervenções alternativas.

Mapeou-se também o Centro de Referência de Assistência Social (CRAS) da Reserva de Dourados como órgão fundamental a ser articulado no desenvolvimento dessas ações. Contudo, não ocorreu discussão nesta terceira instância, pois o CRAS Indígena estava em um momento de transição, funcionando com apenas uma assistente social, a qual estava sobrecarregada e priorizou outras atividades em andamento (note-se que a população da Reserva de Dourados, naquele ano, era estimada pela Coordenação Regional da FUNAI de Dourados em 12 mil pessoas). Entretanto, essa agente do CRAS reconheceu, como os demais, a necessidade de implementar ações para reduzir o uso de bebidas alcoólicas e drogas na Reserva.

Até onde foi possível acompanhar estas discussões, a posição da FUNAI, documentada em relatórios e no plano de trabalho para a execução das ações de enfren- 
tamento à violência, foi pela implantação do CAPS AD ou equipamento semelhante.

Um dos aspectos relevantes a se destacar nesse processo é quanto o Estado e seus órgãos inexistem enquanto entidade monolítica. São, sobretudo, processos e práticas em que diversas posições são negociadas e disputadas, onde as variáveis incluem questões de ordem técnica, política (inclusive partidária), administrativa e orçamentária. Nas etnografias que abordam e discutem a ação do Estado, desde fora, isso nem sempre se torna evidente. Isso porque o antropólogo está posicionado num campo de relações que demarca o alcance de suas observações. Então, abordagens deste tipo e as que investigam políticas públicas nas pontas, da perspectiva da população à qual se direcionam, complementam-se no sentido de produzir uma compreensão ampliada para repensar as ações do Estado.

Voltando ao ponto anterior, as políticas públicas embasadas em equipagem de serviços deveriam ser colocadas em suspeição. Em reuniões intersetoriais não foram poucas as constatações de um discurso de prestação de contas de atividades restrito a um quantitativo de profissionais, veículos, postos de saúde, equipamentos etc., sem levar em conta ações e processos em andamento, ou ainda, os desafios e impasses enfrentados na implementação das políticas públicas.

De certo ângulo, porém, esse esforço de construir uma ação focada na oferta de equipamentos e não em práticas de atenção, ou mesmo envolvendo outras ações para além da esfera da saúde, faz sentido se ampliamos o escopo da análise para as relações globais. Os efeitos de Estado não se dão exclusivamente por intermédio de instituições nacionais, como afirma Trouillot (2001). Diferentemente de grande parte dos povos indígenas no Brasil, os Kaiowa e Guarani não têm como apelar ao movimento ecológico internacional por sua defesa, pois suas florestas já estão devastadas e suas terras privatizadas. Seu apelo intercede, em geral, organizações internacionais de direitos humanos. Nos últimos anos, em virtude disso, o Itamaraty tem sido chamado a responder, frequentemente, a questionamentos envolvendo violências e as altíssimas taxas de suicídio ${ }^{9}$ entre os Kaiowa e Guarani.

Ao que parece, o nível de violência interna na Reserva de Dourados será reduzido apenas quando todas as melhores ações planejadas estiverem implementadas e, além disso, for possível também reduzir a densidade populacional daquela Reserva Indígena. Isso implica em maior disponibilidade de terras indígenas para os Kaiowa e Guarani por meio da concretização dos processos de 
demarcação de terras obstruídos pelos interesses do agronegócio ${ }^{10}$.

Brand (1997), Pereira (2004), Vietta (2007), entre outros, têm demonstrado que as radicais mudanças sociais decorrentes do confinamento nas Reservas Indígenas inviabilizaram os mecanismos culturais, historicamente utilizados pelos Kaiowa e Guarani, para lidar com as animosidades e disputas políticas inerentes a sua organização social. Porém, do ponto de vista da execução de políticas públicas visando à prestação de contas para a Comissão Interamericana de Direitos Humanos, por exemplo, a mera implantação de equipamentos do tipo CAPS AD pode ser considerada uma medida efetiva.

\section{Como o Estado imobiliza os Kaiowa e Guarani}

As bebidas alcoólicas produzidas a partir da fermentação de alimentos vegetais, particularmente do milho, ocuparam, durante séculos, o centro da vida social entre todos os povos guarani ${ }^{11}$. As festas de confraternização, o ritual de nominação, a celebração da colheita, os mutirões para a construção de casas e produção de alimentos e, entre os Kaiowa, o ritual de passagem dos meninos para a vida adulta, ocorriam em torno do consumo da chicha ou kãgui, como chamam esta bebida fermentada. A substância alimentícia transformada na boca das mulheres jovens convertia-se em dádiva, em alimento divino e num veículo para a produção de alegria e de uma convivência harmonizada.

Em Mato Grosso do Sul, na atualidade, os Kaiowa e Guarani não conseguem produzir chicha em quantidade suficiente para suas festas e rituais, que se tornaram obsoletos diante de processos de rápida transformação social e ambiental decorrentes da expansão econômica no centro-oeste brasileiro. Na Reserva de Dourados, alguns ñanderu e ñandesy, homens e mulheres xamãs, retomaram os rituais mesmo assim, mas não é possível saber até que ponto essas iniciativas conseguem reavivar o sentido de bem-viver produzido pelo consumo coletivo e desmedido da bebida alcoólica tradicional.

Ao mesmo tempo, os Kaiowa e Guarani adotaram o consumo de cachaça, agora de modo individual ou partilhado entre bem poucas pessoas, porém sistematicamente desvinculado de eventos sociais mais amplos. Beber sozinho e beber sempre são sinais de consumo abusivo na perspectiva de alguns Kaiowa e Guarani. Adolescentes e jovens, em especial, incorporaram este novo estilo de consumo às substâncias psicoativas.

Entretanto, esta mudança na bebida consumida não deve ser atribuída apenas 
à escassez dos ingredientes tradicionais, pois traz implicado todo um histórico de dominação e pacificação dos índios no Brasil. Mota apud Oliveira (2001), por exemplo, relata que nos primeiros aldeamentos kaingang no sul do Brasil foram instalados alambiques para fabricar açúcar e aguardente. Também Fernandes (2002) mostra que entre os objetos de troca usados nas estratégias de pacificação dos Mura, na Amazônia, estava a própria cachaça. Entre os Kaiowa e Guarani, Vietta (2007) aponta, citando Arruda, que no trabalho com a erva-mate, uma das maneiras de aliciar mão de obra era promover bailes regados à cachaça, em que os recrutadores persuadiam possíveis trabalhadores com adiantamentos e descrições enganosas dos ervais.

Como mencionado antes, o consumo exagerado e individualizado de bebida alcoólica aparece como um "detonador” para vários tipos de manifestação violenta, como agressões físicas, estupros, tentativas de homicídios e suicídios. Silva etal. (2014) descrevem, de um lado, como esses episódios de agressividade explosiva produzem medo e motivam, por vezes, o abandono de parentes, que passam a perambular na aldeia ou na cidade. De outro lado, eles mostram que as perturbações individuais são bastante associadas a agressões xamânicas, do que muito falavam os Kaiowa e Guarani da Reserva de Caarapó (ver também Pimentel, 2006). Os comportamentos antissociais se explicam, na chave cosmológica, em geral, como resultado de feitiçaria ou pela ação dos anguery, os espectros dos mortos.

O mal-estar gerado entre os Kaiowa e Guarani por conta dessas situações de extravasamento de raiva, ciúme ou vingança levanta polêmicas internas e produz diferentes opiniões. Os aborrecimentos da vida diária, com as pressões e transformações impostas pelo confinamento, levam a conflitos intergeracionais e ao enfraquecimento dos laços familiares, os quais podem produzir um estado de fechamento em si mesmo conhecido como ñemirõ (Mura e Barbosa da Silva, 2012). A pessoa assim é lançada, rapidamente, num misto de desespero, braveza e tristeza, como descreveu Tonico Benites para Pimentel (2006), crise que pode culminar em bebedeiras e atos violentos.

As queixas de que os jovens não querem mais ouvir os conselhos dos pais e outros parentes mais velhos são recorrentes entre os Kaiowa e Guarani. Izaque João (com. pess., 2017), pesquisador kaiowa, identifica mesmo um certo isolamento social dos velhos, que se ressentem pela falta de interesse em seus conhecimentos sobre o sistema kaiowa, o ava reko. Por outro lado, como assegu- 
ram Martins etal (2010), estudantes indígenas, os adolescentes acham ofensivo serem criticados e pressionados por não valorizar “a cultura”. A questão é que a vida aldeã é uma experiência radicalmente diferente entre as distintas gerações: pela paisagem, proximidade das casas, o que se faz no dia a dia, eventos sociais, entre muitas outras facetas da vida.

Por outro lado, não se pode perder de vista que o consumo coletivo e intenso de bebidas alcoólicas ainda carrega o sentido de produção de alegria e agregação social em muitos eventos festivos e rituais que ocorrem no interior da Reserva. Como mostra Heurich (2015) entre os Mbya, o uso ritualizado da bebida fermentada e uso da cachaça em bailes não se constituem como contextos antagônicos, a questão não é tão simples, ainda que a bebida tradicional remeta à comunicação com as divindades e o uso da cachaça à comunicação com os espectros dos mortos.

Quanto à violência, muitos indígenas que vivem na Reserva são favoráveis a seu controle através da polícia dos não-índigenas, enquanto outros se colocam radicalmente contra mais uma intromissão externa. As opiniões a favor da intervenção policial prevaleceram diante do Estado. Enquanto se discutia, em Brasília, a respeito da implantação ou não de um CAPS AD Indígena em Dourados, policiais da Força Nacional e da Polícia Federal, apoiados por agentes da FUNAI, faziam rondas sistemáticas nas aldeias Bororó e Jaguapirú, que compõem a Reserva Indígena de Dourados, além de atender denúncias de violência em outras aldeias e acampamentos.

A Reserva Indígena de Dourados, é bom que se diga, é o caso emblemático da situação dos Kaiowa e Guarani, pois, entre todos os seus assentamentos no centro-oeste brasileiro, aí o adensamento populacional é mais severo. Criada em 1917 com cerca de 3.500 hectares, as estimativas ficavam, em 2012, entre 12 e 14 mil pessoas vivendo naquele espaço. De modo que a densidade populacional na Reserva tornou-se bem maior do que a do próprio município de Dourados, onde se encontra a maior parte do seu território (FUNAI, 2012). No entanto, outras Reservas e Terras Indígenas em que os Kaiowa e Guarani estão sedentarizados também apresentam altos índices de violência.

Antes do desenvolvimento econômico do estado de Mato Grosso do Sul ser estimulado pelo poder central, quando a região era ainda um "mato grosso", a ocupação do espaço pelos Kaiowa e Guarani não era essa dos aldeamentos. O território que abrange parte do centro-oeste brasileiro e a região oriental do 
Paraguai configurava-se a partir de uma intensa e instável rede de alianças e inimizades. As parentelas estavam assentadas sem uma conformação espacial definida ou definitiva, de maneira bastante irregular e em regime de grande itinerância (Lehner, 2002; Mura e Barbosa da Silva, 2012). Uma das primeiras providências tomadas quando boa parte das florestas já havia sido desmatada, foi coibir e proibir a circulação dos Kaiowa e Guarani na região (Brand, 1997,2014).

A literatura produzida sobre os povos guarani aponta, recorrentemente, para a importância do ato de caminhar, tanto no sentido pragmático de usar os recursos da floresta na economia da vida diária, como nos planos cosmológico, sociológico e político. Análises descritivas a esse respeito são recorrentes nas etnografias sobre os Guarani (ver, por exemplo: Chamorro, 1995; Montardo, 2009; Pissolato, 2007). Não há espaço para aprofundar aqui esse ponto, mas a hipótese de que o cerceamento à liberdade de transitar livremente pelo território e assim, de todas as práticas que se compunham a partir deste caminhar, não ocorreu sem consequências no que hoje se entende como violência interna nas aldeias (Pereira, 2004; Souza Lima, 2012), corrobora esta perspectiva.

Embora tenha sido criado para os Kaiowa que já habitavam aquela área antes do estabelecimento da Colônia Agrícola Nacional de Dourados, o então Posto Indígena Francisco Horta Barbosa constitui-se como um espaço multiétnico desde o princípio (Pereira, 2014), ocupado pelos Kaiowa, Guarani e Terena. A vinda destes últimos ocorreu em parte espontaneamente, mas era estimulada, também, por agentes indigenistas e missionários com o fim de ensinar práticas de trabalho e civilidade, pois os Terena eram reconhecidos como trabalhadores rurais (Ribeiro, 1986) e considerados mais civilizados em relação aos Kaiowá e Guarani. O lugar, conforme Pereira (ibid.), logo se tornou um centro de oferta de serviços, começando pela Missão Evangélica Caiuá, instalada em suas cercanias apenas uma década após a criação do Posto Indígena, posteriormente reconhecido como Reserva Indígena, para oferecer assistência médica, escolarização, serviços religiosos e um orfanato.

De alguma maneira, o estereótipo que atribui maior civilidade aos Terena ainda hoje é atualizado no interior da Reserva e alimenta relações assimétricas entre os segmentos étnicos, o que inclui alguns "misturados"12. Conforme Passos (2007), os Terena tendem a se diferenciar por buscarem, há muito tempo, escolarização e profissionalização. Por outro lado, alguns Kaiowa, considerados 
mais tradicionais em relação aos Guarani, questionam a indianidade terena, em momentos de disputa, pelo fato de não falarem sua língua e por sua postura econômica, mais parecida com a dos não-indígenas. Segundo a autora, esta percepção se relaciona ao fato de que serem numericamente minoritários, os Terena detêm boa parte dos lotes na Reserva.

O loteamento das terras foi determinado pelo órgão indigenista na década de 1960 (Pereira, 2014) - outra particularidade da Reserva Indígena de Dourados. Atualmente as duas aldeias, Bororó e Jaguapirú, são totalmente loteadas e estes pequenos espaços de terra, cuja posse é definida por critérios internos (Passos, 2007), são herdados e comercializados. Este é um fator relevante na produção de disputas e conflitos.

No começo da década de 1980, a facilidade de acesso decorrente do asfaltamento da rodovia estadual que cruza a Reserva de Dourados reforçou sua tradição, já citada, de oferta de serviços. Se a possibilidade de assistência aberta, paulatinamente, a todo tipo de entidades com trabalho indigenista serviu como atrativo para mais famílias irem se fixando nesta Reserva Indígena ao longo do tempo, sua explosão demográfica e os problemas daí decorrentes estimularam o afluxo de ainda mais recursos (Pereira, 2014). Hoje a Reserva conta com várias escolas e postos de saúde, espaços para atuação de ONGs e universidades, sedes de secretarias municipais e estaduais, inúmeras igrejas, pequenas mercearias e até um centro poliesportivo.

Paralelamente, o adensamento populacional fez com que cada vez mais homens ingressassem no trabalho remunerado, normalmente em canaviais, passando longos períodos ausentes do convívio familiar. Soma-se a esta prática econômica a nova constante política local: uma acirrada disputa por recursos de agências indigenistas e por prestígio que dê primazia nas relações com seus agentes, em detrimento das relações na própria parentela (Pereira, 2014; Silva etal., 2014; Silveira, 2016). A busca, por parte de algumas lideranças indígenas, pela intervenção de policiais e de agentes ligados a órgãos de controle, tipo conselho tutelar e delegacias especializadas, reveste-se também de certo caráter estratégico, por vezes acionado para enfraquecer adversários na disputa por espaços políticos no interior da Reserva.

Essas feições são semelhantes à Reserva Indígena de Caarapó, local onde o problema da violência tem também grave dimensão. Entretanto, em Dourados há o diferencial do segmento terena da população, o qual tem influência marcante 
nas transformações sociais peculiares a esta Reserva, fazendo com que os Kaiowa e Guarani que se radicaram em Dourados sejam, de certa forma, outros de si mesmos. De acordo com Pereira (ibid.), a convivência contínua entre os segmentos étnicos, ainda que frequentemente ocorram casamentos entre eles, particularmente entre os Terena e os Guarani, acaba por acentuar os contrastes étnicos e as diferenças nas demandas político-administrativas, uma vez que, historicamente, os Terena e os Guarani se concentraram em Jaguapirú e os Kaiowa em Bororó.

\section{Sobre a violência e a guerra}

A relativa imobilização espacial dos Kaiowa e Guarani produzida pelo Estado, correlata à criação das Reservas Indígenas, entre elas a de Dourados, constitui-se como expressão do poder tutelar, produzindo populações onde antes só haviam povos dispersos (Souza Lima, 1995, 2002).

O poder tutelar emerge com a criação de um órgão indigenista, no começo do século XX, instituído para acabar com zonas de conflitos entre os nativos e as populações locais no Brasil. As estratégias e táticas postas em ação através do Serviço de Proteção aos Índios e Localização de Trabalhadores Nacionais (SPI) foram configurando um sistema de governo para as populações nativas que eram, até então, dele alienadas. Souza Lima (1995) mostra como as técnicas de pacificação e atração dos "selvagens" conduziram essas populações à dependência calculada dos recursos do governo, ao mesmo tempo em que localmente encenavam uma forte centralidade dos poderes de Estado, tanto para os índios como para as populações não-indígenas.

As práticas empregadas pelo SPI para transformar os índios em trabalhadores tiveram como pilares seu deslocamento espacial, ou seja, a desvinculação de seus territórios, bem como a tarefa pedagógica de torná-los agricultores civilizados (Souza Lima, 1995). Em termos do que Foucault (2006) designa como arte de governo, o poder tutelar foi um mecanismo essencial de integração territorial no Brasil, o que é muito evidente no centro-oeste brasileiro, que era considerado um vazio populacional há poucas décadas.

Embora, na atual conjuntura, as demandas envolvendo a política indigenista sejam diversas, já que os índios constituíram sua própria visão dos poderes de Estado, algo inexistente em seus primórdios, interessa aqui destacar a continuidade histórica do poder tutelar em relação à guerra da conquista, à invasão européia no continente americano. Essa ideia de uma guerra que adentra o presente, 
conforme Souza Lima (2012), ajuda a entender o quadro projetado na ação de enfrentamento à violência que se tentava operacionalizar no âmbito do Estado.

Conforme Souza Lima (1995), processos históricos de conquista sempre articulam o controle de recursos, em especial da terra, e o status das coletividades pertencentes às unidades conquistadas. De modo que, para exercer poderes sobre o espaço geográfico, foi necessário hierarquizar e alocar de modo diferenciado as populações no Brasil, o que implicou imputar insuficiente capacidade civil aos índios. O órgão indigenista foi responsável pela tutela, com atribuição de proteger e controlar as populações indígenas, até a promulgação da Constituição Federal de 1988.

Considerando o contexto em análise, postula-se que, embora o princípio da tutela não tenha permanecido na atual estrutura jurídico-administrativa estatal, o poder tutelar permanece tanto como diretriz de ação - como um modo de governo dos índios - sobretudo no poder legislativo, quanto como estoque de conhecimentos práticos repassados a novos agentes que atuam junto aos índios na FUNAI ${ }^{13}$ e outros órgãos estatais.

De um lado, o movimento efetivo promovido pela frente parlamentar ruralista do Congresso Nacional, para alterar os mecanismos técnico-burocráticos de legitimação jurídica dos territórios de povos tradicionais, é claramente expressão do poder tutelar, uma vez que pretende revogar na prática um dos quesitos constitucionais que confere cidadania plena aos índios: o direito de viverem em seus próprios termos, sem ter que necessariamente aderir à lógica capitalista.

De outro lado, o poder tutelar emanado da própria FUNAI tem se tornado evidente nos dias atuais, particularmente, no reiterado esforço de manter a hegemonia no campo das políticas indigenistas, com sua responsabilidade de tutora agora reformulada na linguagem de promoção e proteção de direitos indígenas ${ }^{14}$. Desse modo, os recursos e o tempo despendido pela FUNAI para afirmar seu monopólio sobre os índios em instâncias intersetoriais do Estado são bem maiores do que os recursos e o tempo investido em políticas públicas que alcancem a vida dos povos indígenas, como se vê no processo em questão.

O embate que prossegue entre os povos autóctones e as elites brasileiras é notório em Mato Grosso do Sul, onde o conflito fundiário poderia ser, quem sabe, exemplo do que Pedersen (2006) chama de "guerra de baixa intensidade". Isto é, uma situação de violência em que se combinam a herança de um passado colonial, com uma história de violência estrutural que conflui para uma gama 
de estratégias etnocidas e genocidas, ao processo de globalização da economia. Isso se expressa no dia a dia dos índios em Mato Grosso do Sul também como discriminação social (Silveira, 2016). De baixa intensidade ou não, esta é uma guerra declarada por parte das elites rurais locais.

Retomo agora a afirmação de uma imobilidade espacial relativa dos Kaiowa e Guarani como contraponto, para ressaltar que não se trata de um processo de subalternização passiva, bem o contrário. A circulação dos Kaiowá e Guarani entre Brasil e Paraguai ainda é grande e foi recentemente estimulada pela disputa territorial com fazendeiros brasiguaios, na fronteira do Paraguai. Além disso, os movimentos de retorno a locais onde viveram e morreram seus antepassados, caracterizados como acampamentos, multiplicaram-se na última década. Estima-se que há em torno de 15 mil Kaiowa e Guarani vivendo em acampamentos nas margens das rodovias, em áreas reocupadas e em retomadas (Benites, 2012).

Estes acampamentos são considerados por Lutti (2009) uma modalidade alternativa de mobilidade e assentamento, uma estratégia criativa para lidar com adversidades históricas, alicerçada em práticas xamânicas. Morais (2016) define os acampamentos como a face inversa da política tutelar, um ponto de relações firmado na relação sangue-solo que permite alianças sociais diversas daquelas compelidas nas Reservas. Lutti, assim como Morais, fizeram pesquisa em acampamentos no entorno de Dourados e descrevem o grau extremo de precariedade e penúria em que vivem estas famílias, justificável a nossos olhos somente pela expectativa de um futuro em que possam recompor seu modo de viver.

Enfim, poderia-se afirmar, no caso da Reserva Indígena de Dourados, e de modo mais geral entre os Kaiowa e Guarani, que os agenciamentos sociais derivados do poder tutelar criaram uma situação em que o uso cultural de bebidas alcoólicas, predominantemente positivo e agregador (Oliveira, 2001; Langdon, 2013), converteu-se e passa a ser vinculado à violência e ao perigo?

Os dados disponíveis não permitem responder a esta questão, mas levam a ponderar que o problema não está no uso exagerado de bebidas alcoólicas, que ocorria desde quando os Kaiowa e Guarani bebiam, principalmente, chicha. Como discorre Dias (2013) ao tratar do consumo de bebidas alcoólicas entre os índios que vivem no Amapá, na linha do que argumentam Souza e Garnelo (2006), mais do que as quantidades ingeridas, a questão são os efeitos sociais assim produzidos. Nesse sentido, como entender a violência que se manifesta com o uso dessas substâncias: seria a insurgência das novas gerações em face 
ao veto de sua autonomia étnica? Seria expressão do choque entre a ontologia indígena e o poder tutelar? O tema é um tanto complexo e sugere a necessidade de pesquisas interdisciplinares e colaborativas para seu aprofundamento, envolvendo ativamente os próprios Kaiowá e Guarani.

\section{De volta aos processos de atenção}

A discussão em torno da implantação ou não de um CAPS AD na Reserva Indígena de Dourados emergiu de práticas de segurança pública, em que a associação entre violência e uso abusivo de substâncias psicoativas ficou evidente. Havia um viés disciplinador bem marcado em alguns relatórios produzidos a partir destas práticas, relacionado a um interesse em desbaratar quadrilhas de traficantes que aliciavam indígenas, tendo em vista a proximidade com a fronteira do Paraguai.

Por outro lado, é inegável que exista esta demanda pelo equipamento entre os índios de Dourados, pois corria uma proposta paralela de implantação de um CAPS AD Indígena, capitaneada por um deputado federal de Mato Grosso do Sul e encaminhada por ele diretamente ao ministro da saúde. A dúvida que resta é sobre o peso dessa demanda diante do grau de heterogeneidade social na Reserva Indígena de Dourados.

Um terceiro ponto refere-se a uma polêmica entre profissionais da saúde indígena a respeito de o tratamento do alcoolismo ser ou não parte da atenção básica, o que dava margem a se criar a necessidade de um serviço especializado. De fato, no atual modelo de atenção psicossocial instituído no Subsistema de Atenção à Saúde Indígena, a atenção básica é uma instância fundamental para tratamentos ligados a esta esfera da saúde, como é o caso do consumo abusivo de álcool (Jacinto etal., 2016). A polêmica tinha como pano de fundo, certamente, um embate por mais profissionais de saúde para prestar assistência nas aldeias.

Pode-se, então, entender porque, apesar de não haver consenso entre os técnicos ligados ao Ministério da Saúde e à FUNAI sobre a validade de implantar um CAPS AD na Reserva de Dourados, essa proposta continua a ser encaminhada no âmbito de uma política de enfrentamento à violência, articulada pela FUNAI, envolvendo múltiplos agentes de distintos setores do Estado.

Logicamente existe, aqui, o pressuposto de que a implantação deste equipamento significaria prover diagnósticos psiquiátricos, medicamentos e, na linha da recente biologização da psiquiatria (Maluf, 2010), induzir à medicalização 
e medicamentalização de práticas de consumo de substâncias entre os índios. Ainda que o fato de ser um CAPS AD Indígena pudesse levar a algum tipo de especificidade na assistência, indo ao encontro da Política Nacional de Atenção à Saúde dos Povos Indígenas, é bem pouco provável que não fosse redundar na individualização do tratamento, tendo em vista o histórico de experiências acumuladas no Subsistema de Atenção à Saúde Indígena (ver, entre outros, Cardoso, 2014; Garnelo, 2012; Coimbra, 2006).

Mesmo que as políticas de atenção à saúde mental no Brasil tenham sido aperfeiçoadas nas últimas décadas, com a substituição do modelo hospitalar/ asilar por um modelo comunitário de tratamento, para Jacinto etal. (2016) ainda persistem duas limitações quando se trata de aplicá-las à saúde indígena. A primeira diz respeito ao acúmulo destas experiências de cuidados alternativos basicamente em espaços urbanos, onde a lógica de uso do território é bastante distinta. A outra tem a ver com a gestão municipal dos CAPS AD, ao passo que o Subsistema de Atenção à Saúde Indígena é gerido diretamente pelo Ministério da Saúde. Segundo os autores, esta esfera das relações interfederativas ainda precisa ser mais bem ajustada.

Por outro lado, desde o final da década de 1990 têm sido promovidos, no Brasil, debates sobre o consumo abusivo de bebidas alcoólicas entre povos indígenas, a partir de experiências de pesquisa e intervenção cuja premissa é uma abordagem interdisciplinar centrada na efetiva participação dos indígenas (Souza, 2003; Oliveira, 2004; Ferreira, 2004a; Souza etal., 2005).

Nesse sentido, uma iniciativa bem sucedida foi desenvolvida entre os Guarani Mbya no Rio Grande do Sul, no início dos anos 2000. Considerando o uso abusivo de álcool como resultado da história de contato interétnico, formou-se uma equipe composta por cinco xondaro marãgatu para fazer um percurso terapêutico em diversas aldeias a fim de realizar um diagnóstico antropológico participativo. Os xondaro são assistentes do karai, o xamã mbya, em tarefas de cunho sociopolítico. Em reuniões nas aldeias, eles aconselhavam o grupo a respeito do uso de bebidas alcoólicas através das boas palavras e do uso do petyngua ${ }^{15}$, de acordo com a interpretação cosmológica que davam ao tema. Deste modo, foi possível reduzir significativamente o consumo de álcool em algumas das aldeias percorridas pelos xondaro marãgatu (Ferreira, 2004b).

Contudo, os impasses para lidar com um fenômeno tão complexo e heterogêneo são recorrentes (Ghiggi Jr. e Langdon, 2014; Quiles e Barros, 2001). Daí 
resulta a ineficácia de soluções prontas, como também a necessidade de entender as manifestações particulares do consumo das bebidas alcoólicas em diálogo com as populações afetadas e de elaborar ações que articulem as concepções, cuidados e terapias indígenas relativas ao problema.

Assim, diante do quadro descrito antes, de processos, procedimentos e negociações no Estado, a opção pelo equipamento de saúde como resposta ao problema da violência pode ser vista como uma tecnologia de governo alinhada à intenção de monitoramento da violência e, acima de tudo, de controle da conduta dos índios da Reserva de Dourados.

Apesar de transparecer nas discussões intersetoriais sobre as ações de enfrentamento à violência uma clareza dos agentes quanto à amplitude do problema em foco, o uso abusivo de substâncias ficou praticamente restringido à esfera da desordem psicológica no plano de trabalho consensuado. Não se avançou na proposição de ações em saúde alternativas, implicadas à dimensão social do problema, nem foram previstos espaços de co-construção destas ações com os próprios Kaiowa e Guarani, de maneira a buscar a articulação do componente biomédico com as demais ações que foram sugeridas.

Ao mesmo tempo, vale comentar sobre um efeito colateral surgido desse processo. Os agentes da FUNAI deslocados para esta agenda de ações, orientados previamente sobre a proposta, ao se depararem com a gravidade da violência na Reserva de Dourados, começam a buscar recursos disponíveis. Sem alcançar uma articulação local produtiva com a equipe do polo-base da SESAI e do CRAS Indígena, eles passam a promover encontros pontuais de alcoólicos anônimos nas aldeias da Reserva.

Nesse sentido é que o poder tutelar tem rendimento para pensar esta ação do Estado. Ainda que não tenha provocado efeitos palpáveis para os índios que vivem na Reserva de Dourados - e também por isso - todo esse processo mostra que não está em jogo o sofrimento social ou a precarização da vida dos Kaiowa e Guarani, mas a necessidade de monitorar, de manter o caos sob controle para assim fazer perdurar as desigualdades sociais sob a rubrica do étnico.

\section{Comentários finais}

Para elaborar esta análise sobre a ação do Estado no campo das políticas indigenistas, foram associados fatos simultâneos ao planejamento de uma ação direcionada ao uso de bebidas alcoólicas e drogas entre os Kaiowa e Guarani. Essa 
abordagem, de um momento anterior à elaboração de uma política pública, teve por intuito dissolver o modelo nativo de Estado que modulou minhas práticas enquanto agente da FUNAI, tanto quanto a frustração gerada por seus desdobramentos. Se a baliza para a análise fosse outra, como por exemplo, as políticas públicas no campo da saúde mental em curso na Reserva Indígena de Dourados, ou entre os Kaiowa e Guarani, certamente seu conteúdo seria diferente, já que, desde 2002, (Coloma e Vick, 2009) o tema do abuso de álcool nas aldeias vem mobilizando os agentes do DSEI MS.

Recentemente, constituiu-se um Grupo de Trabalho Intersetorial sobre Saúde Mental Indígena, que tem como uma prioridade a situação dos índios em Dourados. A partir desta instância, a instalação de um CAPS na Reserva Indígena de Dourados foi revista, suponho que pelos encaminhamentos terem se deslocado do campo da segurança para o campo da saúde. As premissas para intervenção, então, incorporaram os debates especializados oriundos dos estudos antropológicos e interdisciplinares sobre uso abusivo de bebidas alcoólicas. Particularmente, manter a interlocução com os indígenas ao longo do processo; considerar a diversidade de etnias da Reserva; valorizar e articular ações biomédicas com as práticas dos cuidadores indígenas; e, estabelecer ações preventivas abarcando áreas como saúde, educação, cultura, economia etc. (Jacinto etal., 2016).

Vale ressaltar que o tamanho da população kaiowa e guarani, somente na Reserva Indígena de Dourados, é bem superior à da maioria dos outros povos indígenas no Brasil. Isto impõe o desafio da escala quando se trata de pensar sua participação na formulação e implementação das políticas, ou entender suas perspectivas sobre o uso das bebidas alcoólicas. Há uma heterogeneidade de valores e de modos de viver significativa entre os Kaiowa e Guarani, que corresponde a uma grande variedade de entendimentos sobre o que é o problema e como enfrentá-lo.

A relevância de trazer esta discussão já superada, porém, permanece. A despeito de todo o engajamento e das melhores intenções dos agentes de Estado que buscavam articular esforços em prol dos Kaiowa e Guarani, aos poucos se tornou perceptível um campo de forças em que ser parte de processos estatais é fortalecer a posição do inimigo. Há que se ter em mente que a criação de um órgão indigenista corresponde, segundo Souza Lima (2002), ao êxito das elites brasileiras em manter sua hegemonia diante de mudanças históricas associadas 
ao fim da escravidão e início do regime republicano federativo.

Apontar para uma continuidade do poder tutelar não equivale a uma afirmação de que os agentes da FUNAI, contemporaneamente, neguem o estatuto de cidadão pleno aos povos indígenas, nem a minimizar a importância do protagonismo indígena ou a força política do movimento indígena.

O caso da Aty Guasu é exemplar nesse sentido. Resultado da articulação supralocal de líderes políticos e xamânicos, essas grandes assembléias intercomunitárias vem ocorrendo regularmente desde o final da década de 1970 (Benites, 2012). Além de organizarem entre si as táticas a adotar para ter seus territórios regularizados, agentes de diversos setores do Estado são convidados pelos Kaiowa e Guarani a ouvir reivindicações, face a face, e prestar contas a respeito de políticas públicas específicas. De fato, os avanços das políticas indigenistas estão atrelados, mais que tudo, a uma gama de estratégias criada pelos povos indígenas para reivindicar e fazer valer seus direitos.

Esta análise quer sublinhar, sobretudo, que os modos de fazer a política indigenista, particularmente no que se refere à transmissão de conhecimentos especializados e à disputa por uma hegemonia na promoção dos direitos indígenas na esfera intersetorial, frequentemente se expressam como um exercício de governo fundado no controle dos índios.

O processo de discussão e planejamento de uma ação em saúde mental na Reserva Indígena de Dourados, no âmbito da FUNAI, explicita que, para além da complexidade envolvida no delineamento técnico de uma ação voltada para atenção em saúde mental de povos indígenas, as tecnologias de governo associadas às políticas indigenistas são decisivas para sua implementação.

Recebido: 24/01/2018

Aprovado: 07/04/2018

Nádia Heusi Silveira é doutora em Antropologia Social pela Universidade Federal de Santa Catarina. É pesquisadora associada ao INCT BRASIL PLURAL, na Rede Saúde: práticas locais, experiências e políticas públicas. Coordenou a edição da Revista Tellus, da Universidade Católica Dom Bosco (UCDB), de 2005 a 2013. Contato: nheusi@yahoo.com.br 


\section{Notas}

1. Kaiowá e Guarani é como a maioria dos antropólogos que trabalha com esses povos se refere aos subgrupos falantes da língua guarani que vivem em Mato Grosso do Sul, no Brasil. Essa denominação parte do fato de que a maioria dos Nandeva ou Ava, como também se reconhecem os Guarani, aceita, em certos momentos, ser identificada desta última forma. Por outro lado, os Kaiowa, que em alguns pontos de seu território se autoidentificam como Paî ou Paî-Tavyterã, não aceitam serem chamados de Guarani.

2. Os dados da ação intersetorial foram recuperados a partir de registros de trabalho, memória e documentos técnicos. Outras considerações a respeito dos Kaiowa e Guarani baseiam-se na interlocução com lideranças indígenas e visitas a algumas aldeias em Mato Grosso do Sul enquanto agente da FUNAI. Além disso, foram realizadas visitas e pesquisa de campo, principalmente na Reserva Indígena de Caarapó, no município de Caarapó (MS), nos anos 2004, 2005 e 2006, junto ao Núcleo de Estudos e Pesquisas das Populações Indígenas, na Universidade Católica Dom Bosco. Assim, embora focadas na experiência de agente de Estado, as análises deste texto agregam um longo convívio e experiência etnográfica prévia com os Kaiowa e Guarani. A possibilidade de valorizar o tipo de iniciativas aqui descrito deveu-se ao empenho da demógrafa e antropológa Marta Maria Azevedo, que assumiu a presidência da FUNAI entre 2012 e 2013. Aproveito para agradecer, nesta nota, à antropóloga colega de trabalho na FUNAI, Angela Sacchi, por seus comentários a uma versão preliminar deste artigo.

3. Refiro-me ao uso abusivo de álcool, ou consumo abusivo, sem fazer referência à ingestão excessiva em si, que não parece ser a questão fundamental, como argumento adiante. Considero um embriagar-se que pode ser reconhecido como problemático entre os Kaiowa e Guarani, ligado a comportamentos violentos.

4. Os dados produzidos durante a Operação Tekohá, a qual vinha ocorrendo desde 2011, demonstraram que casos de agressão, estupro, suicídio e homicídio envolvem majoritariamente índios embriagados. Ao acompanhar alguns casos de crianças desnutridas em Caarapó, em 2005, houve relatos das agentes de saúde de que os pais da maioria delas bebiam frequentemente, o que pode ser constatado em algumas visitas às casas da aldeia.

5. Em conversas na Reserva de Caarapó ouvi bastante sobre o uso de cannabis, que estava se constituindo como um problema por volta de 2006, 2007; menos sobre aspirar solventes. Depois, agentes que atuavam na segurança das aldeias, bem como nas Coordenações Regionais, no período de trabalho na FUNAI, relataram que em Dourados o crack já havia entrado na Reserva. Sobre o uso destas substâncias entre os 
Kaiowa e Guarani desconheço qualquer compilação estatística.

6. Intervenções emergenciais e pontuais vêm ocorrendo antes disso, delineadas entre FUNAI e o Departamento de Polícia Federal. Houve quatro edições da Operação Sucury antes da Operação Tekohá, a qual foi motivadora das discussões em tela. A operação baseava-se em rondas de policiamento ostensivo, bem como na busca e apreensão de armas e entorpecentes. Paralelamente, desde 2009 o governo federal negocia com o poder estadual, sem sucesso, um acordo de segurança pública fundamentado na ideia de policiamento comunitário, a ser desenvolvido nas terras indígenas kaiowa e guarani.

7. O CAPS é uma equipamento de saúde implementado em várias modalidades como parte das Redes de Atenção Psicossocial, desde 2011. É uma esfera de serviços estratégica onde equipes multidisciplinares de saúde assistem pessoas com sofrimentos, transtornos mentais ou necessidades derivadas do uso de álcool e drogas, em articulação com outros pontos de atenção em saúde mental. Seu desenho é um desdobramento da Reforma Psiquiátrica. Para um detalhamento dos avanços na atenção psicossocial de povos indígenas ver Jacinto etal. (2016).

8. Os profissionais de saúde não conseguiam acessar as informações geradas nas ações de segurança pública dentro da Reserva Indígena de Dourados; tampouco as queixas ou evidências de violência que chegavam ao posto de saúde eram registradas enquanto tal.

9. O parâmetro considerado aceitável pela Organização Mundial de Saúde é de 12/100 mil habitantes. Entre os Kaiowa e Guarani foram notificados 684 suicídios de 2000 a 2013, conforme Rangel (2014), que equivalem a uma taxa de suicídios entre 75 a 90/100 mil habitantes na série histórica.

10. Em 2008, por determinação de um Compromisso de Ajuste de Conduta firmado com o Ministério Público Federal, a FUNAI iniciou estudos de identificação e delimitação dos territórios kaiowa e guarani em Mato Grosso do Sul. Até 2013, enquanto estive no órgão, apenas Iguatemipeguá, uma das cinco áreas em estudo, havia sido identificada como Terra Indígena. Estes procedimentos foram praticamente paralisados em virtude de negociações entre os poderes legislativo e executivo para alterar os processos de demarcação de terras para povos indígenas e tradicionais. Morais (2016) traz dados atualizados e detalhados sobre o andamento dos processos de demarcação de terras para os Kaiowa e Guarani.

11. Há muitos trabalhos que descrevem a centralidade das bebidas fermentadas na vida dos Guarani, cito apenas alguns clássicos: Nimuendaju (1987); Melià et al (1988) e Bartolomé (1977). Entre as produções contemporâneas, destaco a dissertação ela- 
borada por Izaque João (2011) sobre as rezas kaiowá.

12. Passos (2007) comenta dos misturados ou mestiços como uma categoria social local caracterizada por não ter uma identidade étnica definitiva. São pessoas que nasceram de casamentos entre Terena e Guarani, Terena e Kaiowa, Kaiowa e Guarani ou de indígenas com não-indígenas. Segundo a autora, os critérios para chamar alguém de mestiço são muito variados e flexíveis, de modo que essa categoria é bastante manipulável. No entanto, não fica evidente que papel eles têm na dinâmica sociopolítica da Reserva.

13. O cargo de indigenista especializado, função majoritária até recentemente nos quadros da FUNAI, de nível superior, não exige formação acadêmica específica. Os conteúdos relativos às peculiaridades sociais e culturais dos índios e do campo indigenista eram abordados em cursos de capacitação oferecidos aos agentes do órgão após a contratação. Contudo, para alguém sem conhecimentos prévios, essas capacitações eram insuficientes para orientar a prática profissional. Assim, a tendência predominante é ainda a transmissão horizontal dos conteúdos entre os agentes, para onde confluem perspectivas diversas e, às vezes, divergentes sobre qual deve ser a postura da FUNAI em relação aos índios.

14. Em 2009, houve uma reestruturação da FUNAI, com a revisão do organograma administrativo a partir de direitos territoriais e direitos sociais, a criação de um cargo de indigenista de nível superior (antes eram agentes com formação em segundo ou primeiro grau), uma proposta de descentralização de ações com a criação de coordenações técnicas locais e estímulo ao controle social a partir da criação de comitês gestores regionais. Parte dessas mudanças nunca chegou a se concretizar.

15. Este é o nome mbya dado ao cachimbo em que fumam tabaco. A fumaça produzida com o petyngua promove a conexão cosmológica com as divindades (Cadogan, 1946). Eles não ingerem a fumaça, somente a produzem para solta-la no ambiente ou soprar sobre objetos e pessoas. Os momentos em que a produção de fumaça de tabaco se faz necessária envolvem aconselhamento, xamanismo e busca de proteção (ver, entre outros, Silveira, 2011).

\section{Referências bibliográficas}

BARTOLOMÉ, Miguel Alberto. 1977. Orekuera Royhendu (Lo que escuchamos em sueños). Shamanismo y religion entre los Ava-Katu-Ete del Paraguay. Mexico: Instituto Indigenista Interamericano.

BENITES, Tonico. 2012. "Trajetória de luta árdua da articulação de lideranças Guarani e Kaiowa para recuperar seus territórios tradicionais”. Revista de Antropologia 
da UFSCar, 4(2):165-174.

BRAND, Antonio J. 2014. “Entrevista com Antonio Jacó Brand”. Tellus, 23:179192.

1997. O impacto da perda da terra sobre a tradição Kaiowá/Guarani: os difíceis caminhos da palavra. Tese (Doutorado em História) - PUC/RS, Porto Alegre.

CADOGAN, León. 1946. "Las tradiciones religiosas de los índios Jeguaká Tenondé Porã-gué i del Guairá, comúnmente llamados Mbyá, Mbyá-Apyteré o Ka’yinguá”. Revista de la Sociedad Cientifica del Paraguay, 7(1):15-47.

CARDOSO, Marina D. 2014. "Saúde e povos indígenas no Brasil: notas sobre alguns temas equívocos na política atual”. Cadernos de Saúde Pública, 30(4):860-866.

CHAMORRO, Graciela. 1995. Kurusu Ñe’ëngatu. Palabras que la historia no podría olvidar. Assunção/São Leopoldo: Centro de Estudios Antropológicos da Universidad Católica/Instituto Ecuménico de Posgrado, Escuela Superior de Teología/Consejo de Misión entre Indios. COIMBRA JR., Carlos. et al. 2006. "Sistema em Transição”. In: Ricardo, Carlos Alberto; Ricardo, Fani (Orgs.). Povos Indígenas do Brasil: 2001-2005. São Paulo: Instituto Socioambiental. pp. 141-144.

COLOMA, Carlos; VICK, Fabiane O. 2009. "Epidemiología sociocultural Del Suicidio: El caso de los Kaiowá-Guaraní de Brasil”. Parte I. Revista Reivindicando la Vida, $1: 43-60$.

DIAS, Laércio F. 2013. "Consumo de bebidas alcoólicas entre os povos indígenas do Uaça”. In: Souza, Maximiliano L. P. Processos de Alcoolização Indígena no Brasil:perspectivas plurais. Rio de Janeiro: Ed. da Fiocruz.

FERNANDES, João A. 2002. "Cauinagens e bebedeiras: os índios e o álcool na história do Brasil”. Anthropológicas, 13(2):39-59.

FERREIRA, Luciane O. 2004a. "O “fazer antropológico” em ações voltadas para a redução do uso abusivo de bebidas alcoólicas entre os Mbyá-Guarani, no rio Grande do Sul”. In: Langdon, Esther J.; Garnelo, Luiza (Orgs.). Saúde dos Povos Indígenas: reflexões sobre antropologia participativa. Rio de Janeiro: Contracapa/ABA, pp.89-110. 2004b. “As 'boas palavras' dos Xondaro Marãgatu como alternativa para a redução do consumo de bebidas alcoólicas entre os Mbyá-Guarani - RS”. Tellus, 7: 121-135.

FOUCAULT, Michel. 2006. "Governmentality”. In: Sharma, Aradhana; Gupta, Akhil (Eds.). The anthropology of the state: a reader. Oxford: Blackwell. pp.131-143.

FUNAI. Fundação Nacional do Índio. 2012. Quadro Demonstrativo da Situação Fundiária atual dos Guarani e Kaiowa em Mato Grosso do Sul. Nota técnica $n^{\circ} 16$, Bra- 
sília.

GARNELO, Luiza. 2012. "Política de Saúde Indígena no Brasil: notas sobre as tendências atuais do processo de implantação do subsistema de atenção à saúde”. In: Garnelo, Luiza; Pontes, Ana Lúcia (Orgs). Saúde Indígena: uma introdução ao tema. Brasília: MEC-SECADI/UNICEF. pp.18-59.

GHIGGI JR, Ari; LANGDON, Esther Jean. 2014. "Reflexões sobre estratégias de intervenção a partir do processo de alcoolização e das práticas de autoatenção entre os índios Kaingang, Santa Catarina, Brasil”. Cad. Saúde Pública, 30(6):1-10.

HEURICH, Guilherme Orlandini. 2015. "Outras alegrias: cachaça e cauim na embriaguez mbyá-guarani”. Mana, 21(3):527-552.

JACINTO, Andréa B. M.; MACDOWELL, Pedro de L.; DUARTE, Taia M. 2016. Notícias de meio do caminho: alguns desafios para as políticas de atenção psicossocial na região do Cone Sul do Mato Grosso do Sul. Comunicação apresentada na 30 $0^{\mathrm{a}}$ Reunião Brasileira de Antropologia, GT Antropologia e políticas de saúde. João Pessoa. Disponível em: <http://www.30rba.abant.org.br/simposio/view?ID_MODALIDADE_TRABA$\mathrm{LHO}=2 \& I D \_S I M P O S I O=53>$. Acesso em: 13 mar. 2017.

JOÃO, Izaque. 2011. Jakaira reko nheypyru marangatu mborahéi: origem e fundamentos do canto ritual jerosy puku entre os Kaiowa de Panambi, Panambizinho e Sucuri'y, Mato Grosso do Sul. Dissertação (Mestrado em História) - UFGD, Dourados.

LANGDON, Esther Jean. 2013. "O abuso de álcool entre os povos indígenas no Brasil: uma avaliação comparativa”. In: Souza, Maximiliano L. P. (Org.). Processos de Alcoolização Indígena no Brasil: perspectivas plurais. Rio de Janeiro: Ed. da Fiocruz.

LEHNER, Beate. 2002. Territorialidad Guarani. Ensayo sobre la relación territorio organización socio-politica de los Ava-Guarani y Pai-Tavyterã. Disponível em: <http:// www.guarani.roguata.com/articles/index.php?language $=$ spa $>$. Acesso em: 10 maio 2006.

LUTTI, Aline Castilho Crespe. 2009. Acampamentos indígenas e ocupações: novas modalidades de organização e territorialização entre os Guarani e Kaiowa no município de Dourados - MS (1990-2009). Dissertação (Mestrado em História) - UFGD, Dourados.

MALUF, Sonia W. 2010. "Gênero, saúde e aflição: políticas públicas, ativismo e experiências sociais”. In: Maluf, Sonia W.; Tornquist, Carmem Susana (Orgs). Gênero, saúde e aflição. Abordagens antropológicas. Florianópolis: Letras Contemporâneas.

MARTINS, Clodolina; MACHADO, Indianara R.; DIAS, Thaisa; TIAGO, Zuleica da S. 2010. “A felicidade do adolescer”. Tellus, 18:241-245.

MELIÀ, Bartomeu; GRÜNBERG, Georg; GRÜNBERG, Friedl P. 2008. Paî-Tavyterã. 
Etnografía guaraní del Paraguay contemporáneo. Assunção: CEADUC-CEPAG.

MONTARDO, Deise L. 2009. Através do mbaraka: música, dança e xamanismo guarani. São Paulo: Edusp.

MORAIS, Bruno Martins. 2016. Do corpo ao pó: crônicas da territorialidade Kaiowa e Guarani nas adjacências da morte. Dissertação (Mestrado em Antropologia Social) - USP, São Paulo.

MURA, Fabio; BARBOSA DA SILVA, Alexandra. 2012. "Tradição de conhecimento, processos experienciais e práticas de cura entre os Kaiowa”. In: Garnelo, Luiza; Pontes, Ana Lúcia (Orgs). Saúde Indígena: uma introdução ao tema. Brasília: MEC-SECADI/UNICEF. pp.129-155.

NIMUENDAJU, Kurt U. 1987 [1914]. As lendas da criação e destruição do mundo como fundamentos da religião dos Apapocúva-Guaraní. São Paulo: Hucitec-Edusp.

OLIVEIRA, Marlene de. 2004. "A intervenção como um processo em construção: notas para a redução do uso de bebidas alcoólicas e alcoolismo entre os Kaingáng”. In: Langdon, Esther J.; Garnelo, Luiza (Orgs.). Saúde dos Povos Indígenas: reflexões sobre antropologia participativa. Rio de Janeiro: Contracapa/ABA, 2004. pp.69-87.

. 2001. Alcoolismo entre os Kaingáng: do sagrado e lúdico à dependência. In: Seminário sobre Alcoolismo e DST / AIDS entre os Povos Indígenas. Brasília: Ministério da Saúde / Coordenação Nacional de DST e Aids. pp. 99-126.

PASSOS, Lilianny Rodriguez B. 2007. Associações indígenas: um estudo das relações entre Guarani e Terena na Terra Indígena de Dourados - MS. Dissertação (Mestrado em Antropologia Social) - UFPR, Curitiba.

PEDERSEN, D. 2006. "Reframing political violence and mental health outcomes: outlining a research and action agenda for Latin America and the Caribbean region”. Ciência e saúde coletiva, 11(2):293-302.

PEREIRA, Levi M. 2014. A atuação do órgão indigenista oficial brasileiro e a produção do cenário multiétnico da Reserva Indígena de Dourados, MS. Comunicação apresentada na 38 ${ }^{a}$ Reunião da ANPOCS, GT Metamorfoses do rural contemporâneo. Caxambu. Disponível em: <http://www.anpocs.org/portal/index.php?option=com_docman\&task=doc_view\&gid=8809\&Itemid=456>. Acesso em: 26 out. 2015. 2004. Imagens Kaiowá do sistema social e seu entorno. Tese (Doutorado em Antropologia Social) - USP, São Paulo.

PIMENTEL, Spensy K. 2006. Sanções e Guaxos. Suicídio Guarani e Kaiowa - uma proposta de síntese. Dissertação (Mestrado em Antropologia Social) - USP, São Paulo.

PISSOLATO, Elisabeth. 2007. A duração da pessoa. Mobilidade, parentesco e xamanismo 
mbya (guarani). São Paulo: UNESP/Rio de Janeiro: NuTI.

QUILES, Manuel Ignácio; BARROS, Edir P. de. 2001. “Alcoolismo doença de branco (uma reflexão sobre o conceito de alcoolismo entre os povos indígenas a partir do comportamento alcoólico entre os índios Bororo do Mato Grosso)". Saúde e Ambiente, 4(1/2):35-48.

RANGEL, Lúcia Helena (Coord.). 2014. Relatório Violência contra os povos indígenas no Brasil - Dados de 2013. Brasília: CIMI.

RIBEIRO, Darci. 1986. Os Índios e a Civilização: a integração das populações indígenas no Brasil moderno. 5ed. Petrópolis: Vozes.

SILVA, Antonio; LANGDON, Esther Jean.; RIBAS, Dulce. 2014. "Percepção e cuidados com as pessoas diagnosticadas com psicopatologia crônica nas Comunidades Kaiowá e Guarani de Mato Grosso do Sul”. Dossiê Ciências Sociais e Saúde Mental. Ciências Humanas e Sociais em Revista, 36:7-25.

SILVEIRA, Nádia H. 2016. "Discriminação, impasses sociais em Mato Grosso do Sul e o bem-viver kaiowa e guarani”. In: Langdon, Esther Jean; Grisotti, Márcia (Orgs.). Reflexões sobre pesquisa antropológica e políticas públicas. Florianópolis: EdUFSC. 2011. Imagens de abundância e escassez: comida guarani e transformações na contemporaneidade. Tese (Doutorado em Antropologia Social) - UFSC, Florianópolis.

SOUZA, Juberty Antonio de. 2003. "Percepções sobre saúde, doença e suas implicações na implantação em projetos de prevenção”. In: Jeolás, Leila; Oliveira, Marlene de (Orgs). ANAIS do Seminário Cultura, Saúde e Doença. Londrina: PML/Ed Fiocruz. pp.66-74.

SOUZA, Juberty Antonio de; OLIVEIRA, Marlene de; KOHATSU, Marilda. 2005. Uso de bebidas alcoólicas nas sociedades indígenas: algumas reflexões sobre os Kaingáng da bacia do rio Tibagi, Paraná. In: Coimbra Jr., Carlos E. A., Santos, Ricardo V.; Escobar, Ana Lúcia (Orgs.). Epidemiologia e saúde dos povos indígenas no Brasil. Rio de Janeiro: Editora FIOCRUZ/ABRASCO. pp.149-167.

SOUZA, Maximiliano L. P. de; GARNELO, Luiza. 2006. "Desconstruindo o alcoolismo: notas a partir da construção do objeto de pesquisa no contexto indígena”. ReV Latinoam. Psicopat. Fund., 9(2):279-292.

SOUZA LIMA, Antonio Carlos. 2012. "O exercício da tutela sobre os povos indígenas: considerações para o entendimento das políticas indigenistas no Brasil contemporâneo”. Revista de Antropologia, 55:781-832. . 2002. "Introdução". In: (Org) Gestar e gerir. Estudos para uma antropologia da administração pública no Brasil. Rio de Janeiro: Relume-Dumará. 
1995. Um grande cerco da paz: poder tutelar, indianidade e formação do Estado no Brasil. Petrópolis: Vozes, Rio de Janeiro.

TROUILLOT, Michel R. 2001. "The Anthropology of the State in the Age of Globalization: Close Encounters of the Deceptive Kind”. Current Anthropology, 42:125-138.

VIETTA. K. 2007. Histórias sobre terras e xamãs kaiowa: territorialidade e organização social na perspectiva dos Kaiowa de Panambizinho (Dourados, MS) após 170 anos de exploração e povoamento não indígena da faixa de fronteira entre o Brasil e o Paraguai. Tese (Doutorado em Antropologia Social) - USP, São Paulo. 
Resumo: Este artigo aborda a ação do Estado tendo em vista o processo de discussão de uma política intersetorial direcionada ao problema do uso de álcool e drogas entre os Kaiowa e Guarani. Os agentes envolvidos realizaram uma serie de encontros e debates para consensuar diretrizes de ação, tendo como um dos eixos de debate a instalação ou não de Centro de Atenção Psicossocial Álcool e Drogas (CAPS AD) na Reserva Indígena de Dourados. Considerando convergências e divergências de pontos de vista a partir da unanimidade sobre a necessidade de implementar uma ação articulada entre vários órgãos de governo, o caráter desses encontros é analisado considerando a perpetuação do poder tutelar.

Palavras-chave: violência; bebidas alcoólicas; Kaiowa e Guarani; Estado; política indigenista
Abstract: This article approaches the State action in the viewing of the process of discussing an intersectoral policy focused on the problem of alcohol and drug use amongst the Kaiowa and Guarani. The agents involved held a series of meetings and debates to agree on guidelines for that action, when one of the axes of discussion was the establishment of a Psychosocial Alcohol and Drug Attention Center (CAPS AD) at Dourados Indigenous Reserve. Considering convergences and divergences of points of view starting from the unanimity on the need to implement an articulated action among several government sectors and the character of these meetings are analyzed considering the perpetuation of the tutelary power.

Keywords: violence; alcoholic beverages; Kaiowa and Guarani; State; indigenist policy 